\title{
Rethinking Paternalistic Leadership : A Distributive Justice Perspectives
}

\author{
Dodi Irawanto, Joshua Manullang \\ Management Department, University of Brawijaya \\ dodi.wi@ub.ac.id
}

\begin{abstract}
The growing interest in looking paternalistic leadership (PL) effectiveness has much been seen from the organizational output perspectives. A studies of PL development over time is seen the transactional aspects of organizational effectiveness. The concept of how organizational justice, in this review we focusing on distributive justice are rarely discussed. A model of PL that originating from Chinese where proved to be effective implemented in Indonesian context is presented in a way that distributive justice plays a vital role in making the implementation success. Research propositions based upon the origin model as well as the specific Indonesian leadership cultural model are offered to encourage further studies synergizing PL and distributive justice.
\end{abstract}

Keywords : Paternalistic Leadership, distributive justice, organizations, propositions, synergizing

\section{Intoduction}

To days the Leadership style research is still evolves especially when it comes to determine which leadership style are effective to be implemented in organizations, since culture, leadership, and organizations are interrelated (Thom, 2006). To Indonesian culture, Leadership culture itself where emphasize the collectivist culture, style such as Paternalistic Leadership which is composed to three style, which is authoritarian style, benevolent style, and moral style (Wu, Huang, Li, \& Liu, 2012) were found to be effective implemented.

In relate to organizational justice in the light of leadership (Jasso, Sabbagh, \& Törnblom, 2016) found that distributive justice as a condition when members of organization feel fair and equal, when rewards they receive from leader, are equal to effort they give to organizations they fell more comfortable. On the other side if, members of organization feel the leader treat them with fairness, and equal, the leader itself become favorable for members of organization (Scandura, 1999) The other benefit from distributive justice itself is diminished work stress, fewer complaints, and also good health behavior (Lucas, Zhdanova, \& Alexander, 2011).

Paternalistic leadership is predicted that can actually synergizing with distributive justice itself, although according to (Jackson, 2016) pointed out the negative connection associated with paternalistic leadership style, which is paternalistic leadership is so personal, it is also dependent on the quality of individual relationship between leaders and individuals of members of organization itself. As a result, thereis a possible chance that distributive justice will not be implemented in bottom ground rather than as a lip services, since it will show favoritism and special treatment to particular individuals or groups in organizations. This is when nepotism can possibly happen throughout organizations, when leader relies on personal feeling and opinion about its members. Although, again according to (Jackson, 2016) the relationship between paternalistic leadership and nepotism still not clear.

In Indonesia, collectivist culture become the influencer for leadership style that being use 
until this day. Especially, in Javanese culture that influenced heavily on Indonesian leadership style (Irawanto, Ramsey, \& Tweed, 2012). Especially during the period of the Soeharto regime, when Javanese culture influence become more stronger in Indonesia that the regime allowed Javanese culture to spread and strengthen the influence through out Indonesian formal organization life (Irawanto, Ramsey, \& Tweed, 2012). This review highlights how effective it is that Paternalistic leadership are associated with distributive justice. By exploring the literatures, focusing on Indonesian culture, the review also intended to briefly overview the practical implications of distributive justice on Paternalistic leadership to avoid any negative consequences relates to the culture.

\section{Review}

A paternalistic leadership (PL) model presented by (Irawanto, Ramsey, \& Tweed, 2012) shows how this model work for Indonesia compare to other PL model, which Taiwan PL model or Turkish PL model. The research involves four factors on PL, which visible leadership, Authoritarian Leadership, Benevolent leadership, and Moral Leadership (Irawanto, Ramsey, \& Tweed, 2012). Visible leadership is what members expectations about their leaders, since in Javanese culture, leaders are view as figurehead for the members, and they will follow what leaders do in organization (Irawanto, Ramsey, \& Tweed, 2012). Authoritarian leadership is basically a very strict behaviour that shown by the leaders, and absolute authority on all members (Cheng, Chou, Wu, Huang, \& Farh, 2007). Benevolent leaderships relates to how importance that leaders should concerns about individuals or familial wellbeing (Cheng, Chou, Wu, Huang, \& Farh, 2007). Moral leaderships is related to setting an example by showing superior virtues on leaders, and also shows selfdiscipline, so members would follow (Cheng, Chou, Wu, Huang, \& Farh, 2007).

These four critical factors are basically reflect on how PL in Indonesia work, especially Javanese Culture. Visible leadership related to Indonesian view their leaders as figurehead, and need to be respected, while authoritarian leadership related to "bapakism", or relation between father and son, benevolent leaderships is related to Indonesian view the leaders as a leader that cares about the wellbeing, and needs, and moral leadership is related to Indonesian view the leaders as a person that had superior virtues, and self disicpline (Irawanto, Ramsey, \& Tweed, 2012).

The differences between Indonesian PL model and other PL model is that instead other PL models encourage employee into more self-directed and motivated individuals, Indonesia PL models encourage to more "family" organizational (Irawanto, Ramsey, \& Tweed, 2012). Which means, that personal feeling, and connection between leaders and members are much more emphasize in Indonesia. Which is also shown that PL model in each country are different, depends on the influence of each culture, including Indonesia. In relate to organizational justice, distributive justice arepredicted can be applied in Indonesia PL model . Critical culture blockade such as Indonesians are typically involves on feeling and personal connections between individuals or groups, and provide protection and care from leaders, but loyalty and deference in return (Jackson, 2016). So there is possibility that PL hinders out distributive justice to be achieve in organizations.

Paternalistic leadership: The missing link in cross-cultural leadership studies? (Jackson, 2016) notes the missing link in cross-cultural leadership studies. (Jackson, 2016) pointed out that paternalistic leadership might be effective when implemented on countries that hold 
collectivist, however PL demand their members to obedience and loyalty in other words authoritarian, some assert benovlence should be there only because the power holders or leaders want something on return, as a result personal relationship and connection must be established between leaders and individuals or groups of members itself. (Aycan, 2006) clarify the concepts between benovelent paternalism and exploitative paternalism. Benevolent paternalism is basically a leader that has genuine concnern towards subordinates welfare, in return empolyees showing loyalty and deference towards the leader, while exploitative paternalism is when a leader care towards the employee only to get the compliance from employess to achieve executive goals, and can take away any resources that individuals or groups needs if loyalty and deference are not given to leader. To this, the missing link between the implementation of cultural based leadership model with the implementation of distributive justice getting obvious.

(Aycan, 2006) also distinguished authoritarian management and authoritative management, which authoritarian management relies on control and exploitation of the individuals or groups who in turn shows conformity and dependence in order to receive rewards and/or avoid punishment. Authoritative management still relies on control, but has the underlying motivation to promote the individuals or groups welfare, while individuals or groups must respect the leaders decision and rules, as they will get the benefit from it. This when PL could be possibly synergized with distributive justice, although it in reality considering the cultural values of collectivism it depends again on leader itself, which moral value the leaders held.

\section{Distributive Justice : Paternalistic Leadership Perspectives}

\subsection{General Distributive Justice Overview}

Part of organizational justice, distributive justice is basically involves evaluations of the fairness of outcomes, allocations, or distribution of resources (Lucas, Zhdanova, \& Alexander, 2011). It also heavily involves on how members perceiving distributive justice works, since each individuals or groups perceive justice differently (Jasso, Sabbagh, \& Törnblom, 2016). (Lucas, Zhdanova, \& Alexander, 2011) also stressed that distributive justice are separated into two social identity theory, which is "personal self" and "social selves". Personal self defines the individuals in terms of perceiving themselves, including his or her attributes, and wellfare. While social selves defines the individuals in terms of perceiving his or her own groups in organization.

Viewing the individual aspects of justice, the personal factor intends view distributive justice as personal needs, or rather value their own well being (Lucas, Zhdanova, \& Alexander, 2011). While, social selves intends view disributive justice as others or groups needs, or rather value others or groups own well being (Lucas, Zhdanova, \& Alexander, 2011). Although, again distributive justice are view either personal or social selves by their own identities. Each one, had other personal view about how should distributive justice works. Since, every individuals comes from different background such as, economic background, attittude, and also culture itselfs. Moreover, (Jasso, Sabbagh, \& Törnblom, 2016) proposed a models to describe distributive justice, which is called The Silk Road Justice. In the world of distributive justice, there are three key actors who played role to determined whether distributive justice will be implemented or not, and four key terms to actually implmented distributive justice in orgainzation, which is: 


\section{a) Actors; Allocator, Observer \\ b) Rewardee Key terms : Actual Reward; Just Reward; Justice Evaluation; Justice Consequences}

From the observer point of view, the main intention is to form ideas about just reward for the rewardee itselfs, while allocator assigns the actual reward to the rewardee (Jasso, Sabbagh, $\&$ Törnblom, 2016). The observer determine of how justice or injustice of the actual reward to the rewardee, and generates what we called as Justice Evaluation, while the assessment of how it actual works, are done by observer, which generates what we called as Justice Consequences. In a situation, one person can play each different parts of roles, or maybe both of them, which Allocator and Observer, or also can play all three parts (Jasso, Sabbagh, \& Törnblom, 2016).

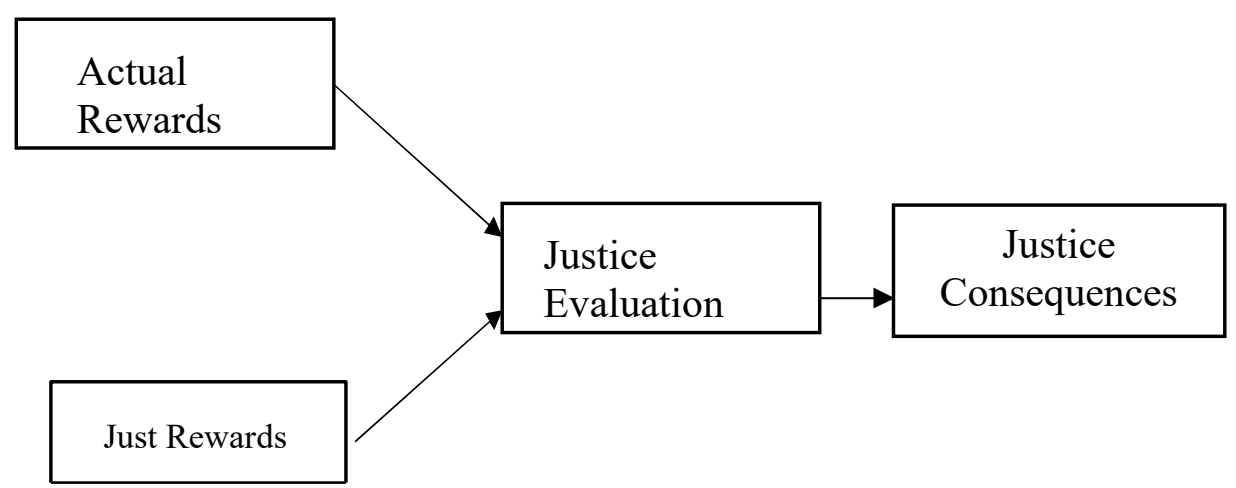

Fig.1. The World of Distributive Justice

Figure 1 explains that how observer form the ideas about how distributive justice should work in his or her organization. The observer doing some comparison between actual rewards, and just rewards, then generates justice evaluation, and finally then sets in motion the justice consequences (Jasso, Sabbagh, \& Törnblom, 2016). This process itselfs heavily involves on rewardee characteristic, observer characteristic, allocator characteristic, together with reward characteristic, also social and cultural context (Jasso, Sabbagh, \& Törnblom, 2016). As a result, this process that leading to actual rewards and justice concequences, may result differently (Jasso, Sabbagh, \& Törnblom, 2016). It depends heavily on personal preference of each person that involves on those three actors.

The main concept that distributive justice are heavily depends on how members of the organizations percieved justice itselfs has been acknowledged by theorist. Including one major factors, which is cultures that heavily influence of each individuals or groups (Thom, 2006). And, it makes Distributive Justice are harder to achieve, since every individuals or groups comes from different cultural background, although in this case, Indonesia, Javanese Culture basically heavily influenced on most part of Indonesia.

\subsection{Distributive Justice in The Eye of Paternalistic Leadership}

Paternalistic leadership (PL) is a leadership style that combines discipline, authority, and power with fatherly benevolence (Karakitapoglu-Aygun, Gumusluoglu, \& Scandura, 2020). 
Three critical factors of PL which authoritarian leadership, benevolence leadership, and also moral leadership are rooted on the local culture (Cheng, Chou, Wu, Huang, \& Farh, 2007). Authoritarian leadership is a style that basically a leader assert absolute authority and control ove subordinates and demand obedience from subordinates, while benevolence leadership is a style that leader shows concern about subordinates needs, while moral leadership is basically a leader that demonstrates superior virtue, self-discipline, and unselfishness (Cheng, Chou, Wu, Huang, \& Farh, 2007).

Paternalistic leadership is basically like father and son relationship, or bapakism (Irawanto, Ramsey, \& Tweed, 2012). In Indonesia itselfs, Javanese Culture heavily influenced across Indonesia, and one of the parts of culture that heavily influenced on leadership style in Indonesia is bapakism culture (Irawanto, Ramsey, \& Tweed, 2012). Although, when paternalistic leadership are implemented in organization, especially Indonesia, there is a potential consequences that distributive justice may not implemented effectively, since paternalistic leadership requires on personal feeling, and connection between leaders and subordinates (Jackson, 2016).

According to (Jackson, 2016), authoritarian basically demands subordinates to show loyalty and deference to leaders, which basically there's a possible conflict between leaders and subordinates that never give loyalty and deference to leaders, and treat others subordinates that give loyalty and deference to leaders with good care, while benovelent leadership basically concerns about subordinates needs, but there is a possibly two situation will happen, either the leaders shows concerns about all subordinates needs, whether some of individuals or groups not shown loyalty and deference, or leaders only shows concerns to some individuals or groups needs that shown loyalty and deference (Jackson, 2016). While moral leadership is when a leaders shown superiror virtue, self-dicipline, and unselfishness (Cheng, Chou, Wu, Huang, \& Farh, 2007), the problem is moral and virtue are basically an ethical issue, and every individuals and groups had their own perspective when it comes to ethical issue itselfs (Jasso, Sabbagh, \& Törnblom, 2016). Unless, leaders and subordinates agreed together about ethical issue stands in organizations.

In Indonesia, collectivist culture becomes part of Indonesia itselfs, and bapakism reflecting PL itselfs (Irawanto, Ramsey, \& Tweed, 2012). However, instead PL model encourage and motivated members, and self directed, Indonesia PL model basically encourage to more "family" organization (Irawanto, Ramsey, \& Tweed, 2012). Which means, more personal feeling and connection heavily involves in Indonesia organization.

(Jasso, Sabbagh, \& Törnblom, 2016) propose distributive justice model which may fit to PL, as a result we will know the process of how the observer actor think about forming ideas about just reward, and also how observer determine how justice or injustice actual reward is to the rewardee. So in order to distributive justice works on organization that leaders using PL style, from who's determine the ideas about just reward, how justice or injustice of the actual reward to rewardee, it's completely up to the leaders, and there's small chance that subordinates can actually intervene about how leaders should form the idea of justice or injustice. Although leaders that using PL style can take bothobserver, and allocator roles, three parts at the same time.

There's a possibility that distributive justice can actually be implemented on PL style, especially in Indonesia, as long leaders implement benevolent paternalism, which is genuine concern towards subordinate needs, in return loyalty and defference should be given by subordinate towards leaders and not exploitative paternalism, which only care to subordinates needs that can help to achieve executive goals, and take away any resources from individuals or group that not given loyalty and deference to leaders (Aycan, 2006). But, it depends again 
on leaders that using PL style, to implemented distributive justice on organization, since each leaders had their own moral to lead organization itselfs. Implications of model presented earlier on Figure 1, is based upon how distributive justice works with PL : P1 : Distributive Justice Compliment The Implementation of Paternalistic Leadership. There is a possibility that distributive justice can actually implemented on patnerlaistic leadership style organization, although there is possibility that authoritarian style can create unfairness on organization, since it's heavily emphasize absolute control and obedience on individuals, and organization, hence. P2 : Authoritarian style of PL contributes to the unfairness of distiributive justice act. Although, two other styles, which moral, and benovelent leadership style can reduce unfairness that resulted from authoritarian styles, but it depends back on leader itself on how virtue, and moral works, also leaders should show unselfish act, which becomes : P3 : Moral and benovelent style of PL contributes to the fairness of distributive justice act.

\section{References}

[1] Aycan, Z. (2006). Paternalism : Towards Conceptual Refinement and Operationalization. In U. Kim, K. Yang, \& K. Hwang, Indigenous and cultural psychology: Understanding people in context (pp. 445-466)). Boston: Springer Science + Business Media. doi:https://doi.org/10.1007/0-387-28662-4_20

[2] Cheng, B.-S., Chou, L.-F., Wu, T.-Y., Huang, M.-P., \& Farh, J.-L. (2007, 08 16). Paternalistic Leadership and Subordinate Responses: Establishing a Leadership Model in Chinese Organizations. Asian Journal of Social Psychology, 7. doi:10.1111/j.1467- 839X.2004.00137.x

[3] Irawanto, D., Ramsey, P., \& Tweed, D. (2012, 02 17). Exploring paternalistic leadership and its application to the Indonesian public sector. International Journal of Leadership in Public Services, 8, 4-20. doi:10.1108/17479881211230637

[4] Jackson, T. (2016, 04 01). Paternalistic leadership: The missing link in cross-cultural leadership studeis? International Journal of Cross Cultural Management, 16, 3-7. doi:10.1177/1470595816637701

[5] Jasso, G., Sabbagh, C., \& Törnblom, Y. K. (2016, 01 01). Distributive Justice. doi:10.1007/9781-4939-3216-0_11

[6] Karakitapoglu-Aygun, Z., Gumusluoglu, L., \& Scandura, T. (2020, 04 19). Paternalistic Leadership How Do Different Faces of Paternalistic Leaders Facilitate or Impair Task and Innovative Perfomance?: Opening the Black Box. Journal of Leadership \& Organizational Studies, 27, 138-152. doi:10.1177/1548051819833380

[7] Lucas, T., Zhdanova, L., \& Alexander, S. (2011, 01 01). Procedural and Distributive Justice Beliefs for Self and Others Assessment of a Four-Factor Individual Differences Model. Journal of Individual Differences, 32, 14-25. doi:10.1027/1614-0001/a000032

[8] Scandura, T. A. (1999). Rethinking leader-member exchange: An organizational justice perspective. The Leadership Quarterly, 25-40. doi:https://doi.org/10.1016/S10489843(99)80007-1.

[9] Thom, W. (2006). Culture, Leadership, and Organizations: The GLOBE Study of 62 Societies [review] / House, R. J., Hanges, P.J., \& Javidan, M., Eds. Journal of Applied Christian Leadership, 55-71.

[10] Wu, M., Huang, X., Li, C., \& Liu, W. (2012, 03 22). Perceived Interactional Justice and Trust- in supervisor as Mediator for Paternalistic Leadership. Management and Organization Review, $97-$ 121. 